\title{
Investigating the Relationship between Emotional Intelligence and Meta-Cognition among Hashemite University Students
}

\author{
Ahmad M. Mahasneh ${ }^{1}$ \\ ${ }^{1}$ Department of Educational Psychology, Faculty of Educational Sciences, Hashemite University, Zarqa, Jordan \\ Correspondence: Ahmad M. Mahasneh, Department of Educational Psychology, Faculty of Educational Sciences, \\ Hashemite University, Zarqa, Jordan. Tel: 962-079-978-0290. E-mail: dahmadmahasneh1975@yahoo.com
}

Received: October 1, 2014 Accepted: October 31, 2014 Online Published: November 14, 2014

doi:10.5539/res.v6n4p201 URL: http://dx.doi.org/10.5539/res.v6n4p201

\begin{abstract}
The aim of this study was to investigate the relationship between emotional intelligence and meta-cognition in a group of university students. The participants were 720 students chosen by random selection from different faculties of the Hashemite University. Means, standard deviations, regression and correlation analysis were used to analyze the data. Results indicated a significant positive correlation between emotional intelligence subscales and meta-cognition subscales, suggesting the need for an enhanced university role in improving student meta-cognition skills through theoretical and applied training programs.
\end{abstract}

Keywords: emotional intelligence, meta-cognition, Hashemite University students

\section{Introduction}

\subsection{Emotional Intelligence}

Despite its historical roots, the concept of emotional intelligence is one of the most recently defined categories of intelligence in the field of psychology, appearing at the beginning of the 1990s as a result of contemporary development which required a nontraditional vision of the concept of intelligence (Pfeiffer, 2001); the demands of the age require individuals to possess the mental abilities and emotional skills needed for problem-solving and influencing others. Mayer and Salovey (1997) suggest the $18^{\text {th }}$ century as the origin of the emotional intelligence concept, when scientists divided the brain into three parts dedicated severally to cognition, affect, and motivation.

The concept of emotional intelligence aroused general interest because of the efficacy of its practical applications in improving the individual's skills in facing the new-age challenges, combined with the dissemination of both concept and basic components through a number of new books and articles by researchers including Bar-on (1988), Garnder (1999), Salovey and Mayer (1983).

Mayer and Salovey (1990) are credited with originating the term "emotional intelligence," considering it a form of social intelligence entailing the individual's ability of both self-control and of influencing emotions and feelings of others; the ability to distinguish different feelings and emotions and use these skills to guide and influence ways of thought and action. These delineations were the result of their attempt to develop a scientific method for measuring the differences between individuals in the field of emotions, during the course of which they found that individuals possessing emotional intelligence skills are able to express their emotions, and recognize, understand, appreciate and regulate the emotions of others (Johnson, 2008). In the early 1990s, Goleman (1995) was interested in the works of Mayer and Salovey, and introduced his vision of the concept, its nature and role in life, in his book "Emotional Intelligence" (1995).

Two years later, Salovey and Mayer (1997) presented a model for emotional intelligence known as the "Ability Model" which defines emotional intelligence as a group of mental abilities that contribute to logical thinking, and that emotions reinforce thinking (Johnson, 2008), promulgating four dimensions of emotional intelligence:

-Perceiving emotions: referring to the ability to identify emotions in the individuals' ideas, language, sounds and behavior. It also entails the ability to distinguish between precision and lack of precision, honesty and lack of honesty in expressing emotions (Mayer \& Salovey, 1997).

-Using Emotions: referring to the way individuals' ideas and other cognitive activities are formed through the 
individuals' emotional experiences. It also entails activating reflection through directing attention towards important data, as well as the ability to discover and use the essential emotions for communicating emotions or using them in other cognitive processes (Johnson, 2008). Mayer and Salovey (1997) suggest that the way we feel is the way we think.

-Understanding \& Analyzing Emotions: including the ability to classify emotions into compound emotions like the individual's feelings of love and hatred, and serial or consequent emotions as when the individual learns that emotions follow a certain sequence or scale of intensity, thus anger increases to fury for example; this dimension also entails the ability to understand the references or meanings implied or expressed by these emotions.

-Managing Emotions: including the ability to manage or control our own emotions and those of others, to control negative emotions and feelings as well as intensify pleasant feelings without suppression or exaggeration. It also includes the ability to be receptive, to control and regulate emotions completely for the purpose of encouraging cognitive and emotional growth.

Goleman (1995) suggested a model for emotional intelligence including five dimensions classified into two main components: (1) Personal components comprising three aspects: emotional self-awareness, regulating and managing emotions, motivation and self-encouragement. (2) Social components comprising two aspects: empathy and social skills.

\subsection{Meta-Cognition}

The first appearance of the concept of meta-cognition and its entrance into the field of cognitive psychology was through the work of John Flavell at the beginning of the 1970s. It was seen as operating the interior cognition mechanisms through which cognitive strategies can be used for controlling other learning processes and extending the range of recollection/retention (Flavell, 1976).

Some researchers refer this type of thinking to three Americans, the two philosophers Johan Dewy and Morris Judd, and psychiatrist Richard Thorndike, who said that students must first know the procedures for solving problems intellectually, then apply that knowledge to new situations (Langrher \& Plamer, 1998).

Some researchers indicate that meta-cognitive thinking has its roots in Piaget's theory of cognitive growth, reasoning that whereas during the materialistic processes stage the child recognizes familiar things and habitual actions, the progression to the abstract processes stage involving deductive thinking, examining assumptions or conceptions mentally, may create a kind of meta-cognitive thinking (Flavell, 1976).

Since meta-cognition plays a significant and sensitive role in promoting successful teaching, it is important to study methods of meta-cognition development among students so that ultimately they improve their application of cognitive processes by mastering meta-cognition (Livingston, 1997).

Henson and Eller (1999), Lindstrom (1995) and Bruer (1995) suggest that meta-cognition attempts to increase learner-awareness of thinking procedures and methods, thereby helping the learner to control, regulate, guide and master the learning processes, the ultimate purpose being the appreciation and comprehension of learning strategies.

Lindstrom (1995) defined meta-cognition as the individuals' awareness of knowledge of their own reflection processes or strategies and their ability to direct and regulate these processes. Similarly, Shah (2009) defined it as the scientific study of the individual's realization surrounding self- knowledge.

Flavell and Wellman (1977) suggest that there are various types of meta-cognitive strategies, some related to knowledge awareness or realization (meta-cognition), which means the individual's self-awareness and control of his cognitive and realization processes, and some to meta-memory which means being aware of the strategies of remembering things as well as controlling and regulating them, while others are related to meta-comprehension and meta-attention which are in turn related to meta-thinking.

Therefore, meta-cognition strategies include the individual's awareness of his thinking style when performing a specific task and then using or applying that awareness to control an action or in the performance of a task (Paris \& Jacobs, 1984).

The most famous of the several models addressing meta-cognitive thinking components is that of Flavell (1979, 1985) who defined two basic components for meta-cognition:

-Meta-cognitive knowledge is composed of three main types: (1) knowing the individual's variables: which include knowing the person himself, his personal beliefs as a thinker or learner, and what he believes regarding others' thinking styles. (2) Knowing the task variables: including knowledge and information 
about the individual's task, which leads to performance as well as furnishing information regarding the prospect of task performance success. (3) Knowing the strategy's variables: including the information held by the individual regarding the meta-cognitive strategies through which they can achieve important personal goals, in addition to the conditional information related to the when, where, and why this strategy is used.

-Meta-cognitive experiences: Cognitive experiences that aid the individual with optimum strategy selection appropriate to the task or problem, whereby various strategies are compared before proceeding to conventional methods such as reviewing the problem considering all aspects and rereading the headings.

Kluwe (1982) suggested a model for meta-cognition that consists of two basic dimensions:

-Knowledge about the individual's thinking and that of others: This is related to the reported or declarative knowledge stored in the long-term memory, consisting of two distinct types: (1) Cognitive declarative knowledge which is knowledge about facts, concepts, and terms. (2) Meta-cognitive declarative knowledge which is knowledge about facts and concepts related to the significant cognitive processes the individual intends to exercise.

-Executive processes related to the two types of procedural knowledge stored in the short term memory: (1) cognitive procedural knowledge such as the individual's knowledge of the processes of adding and subtracting, and related procedures. (2) Meta-cognitive procedural knowledge which includes knowing when, where, how and why this specific strategy is used.

Paris, Lipson and Wixon (1983) suggested a model of meta-cognition including two components:

-Knowledge and control of self: This consists of three sub components: (1) Positive attitudes regarding a certain task which greatly affect the method chosen to confront that task. (2) Commitment, which represents concentrating efforts and skills towards the targeted task. (3) Attention, which represents awareness and focusing on the basic points when performing a certain task.

-Knowledge, control and regulation, having two aspects: (1) knowledge patterns: declarative knowledge which refers to genuine knowledge that is actually available and essential for the individual to know regarding the topic; procedural knowledge which refers to the way something works and how the student solves a certain problem; conditional knowledge which refers to knowing the conditions and reasons that lead to the success of a certain strategy, as well as when and when not to use that strategy. (2) Executive control which includes sub-skills: planning, which includes the intentional choice of strategies that accomplish specific goals; regulation through which we can ensure progress towards achieving goals; evaluation which entails calculating the current state of our knowledge, whether we have the required resources for the task, as well as determining major and minor goals.

However, little research has been carried out concerning the emotional intelligence and meta-cognitive awareness of university students.

\section{Statement of the Problem}

A successful student must be adept at managing information, finding, evaluating and applying new content understanding with great flexibility. This is possible by helping those students who possess the potential for meta-cognition thinking, as well as the emotional balance and competencies relevant to the teaching-learning process. Therefore, the current study problem is to examine the relationship between emotional intelligence and meta-cognition among the students at the Hashemite University in Jordan.

The study aimed at answering the following question: Is there a significant relationship between students' emotional intelligence and their meta-cognition?

\section{Significance of the Study}

The basic goal of this study is to determine the relationships between emotional intelligence and meta-cognition among undergraduates at the Hashemite University (HU) and as such, is important for many reasons: (1) The study contributes to a limited corpus of literature on how the emotional intelligence and meta-cognition of students become important resources for enhancing students' learning, success and quality of education. (2) Meta-cognition has a critical role to play in successful learning techniques. (3) Planning the approach to a task, monitoring, comprehension and evaluation of progress towards task completion, skills that may help students improve their learning competency. (4) Meta-cognition skills and awareness help the person to oversee his own learning process, plan and monitor ongoing cognitive activities and to compare cognitive outcomes with internal or external standards. (5) The relationship between emotional intelligence and meta-cognition in Jordanian university students has not previously been directly examined. 


\section{Method}

\subsection{Participants}

The population of this study consisted of 15,230 undergraduate students enrolled in Hashemite University (HU) faculties in the academic year 2012/2013, and represented all levels of study. For the purpose of this study, a random sample of 720 consisting of 320 male and 400 female students was chosen from the population, their age range 18-22 years.

\subsection{Instruments}

\subsubsection{Emotional Intelligence Questionnaire (EIQ)}

The instrument used in this study was developed by Al-Alwan (2011) after an extensive review relating emotional intelligence measurements (Mayer \& Salovey, 1990; Mayer, Caruso, \& Salovey, 1997, Narimani \& Basharpoor, 2009). The instrument consisted of 41 items grouped into four dimensions related to emotional intelligence: emotional knowledge, 9 items, emotion regulation, 10 items, empathy, 13 items, and social commitment, 9 items. Participants rated each item on a 5 point Likert scale ranging from totally disagree 1 to totally agree 5 .

A Cronbach alpha of 0.76 was reported for the emotional intelligence. In terms of the emotional intelligence dimensions, a reliability estimate of 0.79 was reported for emotional knowledge, $(0.82$ for emotion regulation, 0.70 for empathy and 0.74 for social commitment.

The reliability coefficient was calculated using test-retest and ranged between (0.80-0.86) for emotional knowledge, emotion regulation, empathy and social commitment.

\subsubsection{Meta-Cognition Questionnaire (MQ)}

The MQ was developed by Schraw and Dennison (1994) and permission to use it in the present research study was obtained from the first author. The MQ consists of 52 items rated on a five point Likert scale. Both components of meta-cognition (meta-cognitive knowledge and meta-cognitive regulation) are represented. The inventory includes 17 questions related to the knowledge of cognition factor, for a possible point total of 85.There are 35 questions related to the regulation of cognition factor for a possible point total of 175 . The factor scores are calculated by adding the scores on questions related to each of the factors. Higher scores correspond to greater meta-cognitive knowledge and regulation. In addition to the knowledge of cognition score and the regulation of cognition score, a MQ total score is derived by summing the responses to all 52 questions.

\subsection{Procedures}

The instruments were administered to the participants in their regular classrooms by the researchers who explained the purpose and procedures involved and assuring the participants of anonymity, stressing confidentiality of the responses, which would be used solely for research purposes. The question booklets were distributed and participants instructed on response procedures. On completion, participants' responses were scored by the researchers and entered into the computer for statistical analysis.

\section{Results}

To answer the study question, means and standard deviations of EI and MQ were calculated, the scores obtained from all sub-scales of the meta-cognition scale were good, the values as follows: cognition processing $(\mathrm{m}=3.68)$, knowledge of cognition $(\mathrm{m}=3.31)$, and regulation of cognition (3.18). With respect to emotional intelligence, the values of the sub-scales were also positive: emotional knowledge (3.92), emotion regulation (3.90), empathy (3.96), and social commitment (4).

To explore the relationship between emotional intelligence and meta-cognition, the correlation coefficients were calculated and demonstrated in table 1. 
Table 1. Correlation between emotional intelligence and meta-cognition $(n=720)$

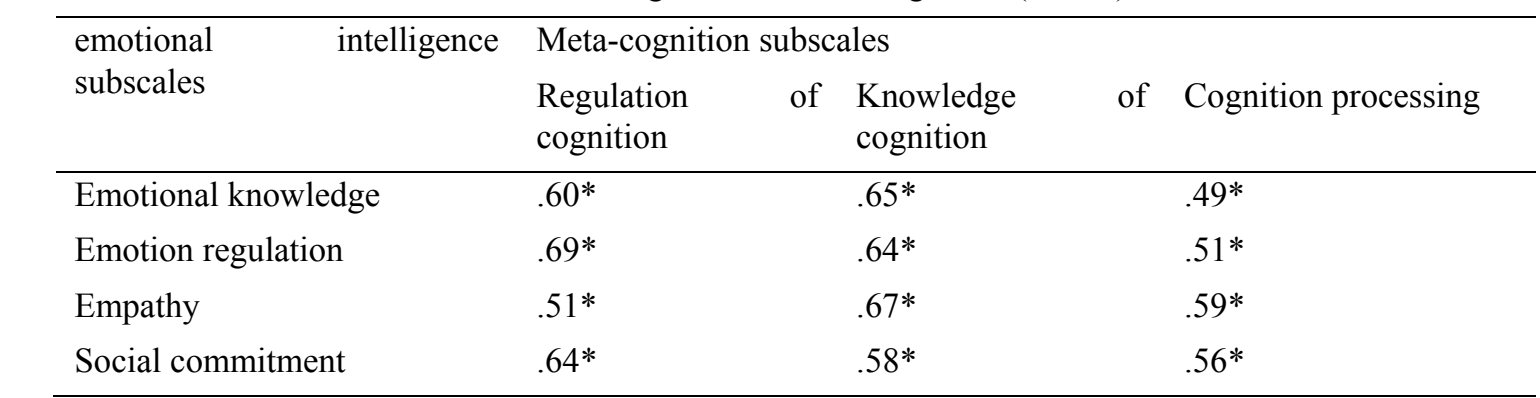

*significant at $(p<0.01)$

Table 1 shows that emotional knowledge is positively related to the regulation of cognition, knowledge of cognition and cognition processing $(p=0.01)$. Emotion regulation is positively related to the regulation of cognition, knowledge of cognition and cognition processing $(\mathrm{p}=0.01)$. Empathy is positively related to the regulation of cognition, knowledge of cognition and cognition processing $(\mathrm{p}=0.01)$. And social commitment is positively related to the regulation of cognition, knowledge of cognition and cognition processing $(\mathrm{p}=0.01)$.

Table 2 shows the results of multiple regression analysis using meta-cognition as predicted to emotional intelligence.

Table 2. Results of regression analyses predicting scores of meta-cognition of emotional intelligence

\begin{tabular}{|c|c|c|c|c|c|c|c|}
\hline $\begin{array}{l}\text { emotional } \\
\text { intelligence }\end{array}$ & Meta-cognitio & & $\mathrm{R}$ & $\mathrm{R}^{2}$ & $\mathrm{~F}$ & $\beta$ & $\mathrm{T}$ \\
\hline \multirow[t]{3}{*}{$\begin{array}{l}\text { Emotional } \\
\text { knowledge }\end{array}$} & $\begin{array}{l}\text { Regulation } \\
\text { cognition }\end{array}$ & of & & & & .293 & 1.204 \\
\hline & $\begin{array}{l}\text { Knowledge } \\
\text { cognition }\end{array}$ & of & .671 & .451 & 8.754 & .600 & 2.295 \\
\hline & $\begin{array}{l}\text { Cognition } \\
\text { processing }\end{array}$ & & & & & -.234 & -.960 \\
\hline \multirow[t]{3}{*}{$\begin{array}{l}\text { Emotion } \\
\text { regulation }\end{array}$} & $\begin{array}{l}\text { Regulation } \\
\text { cognition }\end{array}$ & of & & & & .583 & 2.518 \\
\hline & $\begin{array}{l}\text { Knowledge } \\
\text { cognition }\end{array}$ & of & .710 & .504 & 10.835 & .350 & 1.410 \\
\hline & $\begin{array}{l}\text { Cognition } \\
\text { processing }\end{array}$ & & & & & -.233 & -1.005 \\
\hline \multirow[t]{3}{*}{ Empathy } & $\begin{array}{l}\text { Regulation } \\
\text { cognition }\end{array}$ & of & & & & -.173 & -.718 \\
\hline & $\begin{array}{l}\text { Knowledge } \\
\text { cognition }\end{array}$ & of & .680 & .462 & 9.172 & .669 & 2.585 \\
\hline & $\begin{array}{l}\text { Cognition } \\
\text { processing }\end{array}$ & & & & & .175 & .725 \\
\hline \multirow[t]{3}{*}{$\begin{array}{l}\text { Social } \\
\text { commitment }\end{array}$} & $\begin{array}{l}\text { Regulation } \\
\text { cognition }\end{array}$ & of & & & & .477 & 1.907 \\
\hline & $\begin{array}{l}\text { Knowledge } \\
\text { cognition }\end{array}$ & of & .649 & .421 & 7.750 & .128 & .477 \\
\hline & $\begin{array}{l}\text { Cognition } \\
\text { processing }\end{array}$ & & & & & .074 & .295 \\
\hline
\end{tabular}


Results given in table 2 showed that the regulation of cognition, knowledge of cognition and cognition processing meta-cognition were significant predictors of emotional knowledge $\left(\mathrm{R}^{2}=0.451, \mathrm{~F}=8.754, \mathrm{p}=0.05\right)$. These results were supported by the close moderate correlation between the third variables $(r=0.671)$. Approximated $45.1 \%$ of the variance of the student's emotional knowledge was accounted for by meta-cognition. Regulation of cognition, knowledge of cognition and cognition processing meta-cognition were significant predictors of emotion regulation $\left(\mathrm{R}^{2}=0.504, \mathrm{~F}=10.835, \mathrm{p}=0.05\right)$. These results were supported by the close moderate correlation between the third variables $(\mathrm{r}=0.710)$. Approximated $50.4 \%$ of the variance of the student's emotion regulation was accounted for by meta-cognition. Regulation of cognition, knowledge of cognition and cognition processing meta-cognition were significant predictors of empathy $\left(\mathrm{R}^{2}=0.462, \mathrm{~F}=9.172, \mathrm{p}=0.05\right)$. These results were supported by the close moderate correlation between the third variables $(\mathrm{r}=0.680)$. Approximated $46.2 \%$ of the variance of the student's empathy was accounted for by meta-cognition. Regulation of cognition, knowledge of cognition and cognition processing meta-cognition were significant predictors of social commitment $\left(\mathrm{R}^{2}=0.421, \mathrm{~F}=7.750, \mathrm{p}=0.05\right)$. These results were supported by the close moderate correlation between the third variables $(\mathrm{r}=0.649)$. Approximated $42.1 \%$ of the variance of the student's social commitment was accounted for by meta-cognition.

\section{Discussion}

The concept of meta-cognition was introduced by Flavell in 1976 and his definitions of the main elements of the concept are still in use (Boekaerts \& Simons, 1993; De Jong, 1992; Resnick, 1989; Simons, 2000). Meta-cognition is involved in strategy selection for complex problems requiring recourse tradeoffs, for dealing with unfamiliar situations and for troubleshooting. A number of researchers discuss the fact that meta-cognition can be helpful, neutral, or harmful to cognition and performance (Paris, 2002). Relationship between meta-cognition and emotion as stated above, data regarding the mutual influences among emotion and meta-cognition are unfortunately limited and focused almost exclusively on psychopathology (Matthews \& Wells, 2004; Wells, 2000). For the propose of modeling we need to identify the specific effects of particular affective factor (state or traits) on particular meta-cognition functions and knowledge. The primary purpose of this study was to examine the relationship between emotional intelligence and meta-cognition of university students in different faculties at the HU in Jordan. The results indicated that all EI components are related positively to the three $\mathrm{MC}$ components. These results mean that the regulation of cognition, knowledge of cognition and cognition processing is influenced by the emotional intelligence of the university students. The size of this correlation indicates that generally high level regulation of cognition, knowledge of cognition and cognition processing meta-cognition are related to a high level of emotional knowledge, emotion regulation, empathy and social commitment emotional intelligence.

Emotional thoughts are often accompanied by a host of additional or second order thoughts relevant for perceiving and regulating emotion and emotion management processes. The meta-cognition thoughts can play an important role in understanding psychological processes relevant to emotional intelligence.

Our findings are consisting with other results (Alavinia \& Mollahossein, 2012) which found a positive relationship between learners' emotional intelligence and their use of meta-cognitive strategies. Sharei et al (2012) found that meta-cognition and emotional intelligence contribute significantly to the prediction of problem-solving ability.

Evidence indicates that meta-cognitive control and regulation is comprised of a range of functions including attention allocation, checking, planning, memory retrieval and encoding strategies, and detection of performance errors (Wells, 2000). In general, meta-cognition is involved in strategy selection for complex problems requiring resource compromises, for dealing with unfamiliar situations, and for troubleshooting. A number of researchers discuss the fact that meta-cognition can be helpful, neutral, or harmful to cognition and performance (Paris, 2002).

Concerning the relationship between meta-cognition and emotion as stated above, data regarding mutual influences between emotion and meta-cognition are unfortunately limited, and focus almost exclusively on psycho-pathology (Wells, 2000; Matthews \& Wells, 2004).

From the theoretical standpoint, the following line of research is suggested for the future: (a) The university needs to intensify its role in increasing the effectiveness of students' meta-cognition skills through academic and training programs. (b) The researcher recommends that further studies be conducted using other variables in a different university. 


\section{References}

Al-Alwan, A. (2011). Emotional Intelligence and its Relationship with Social Skills and Attachment Styles of University Students in Light of Specialization and Gender. Jordan Journal of education science, 7(2), 125-144.

Alavinia, P., \& Mollahossein, H. (2012). On the Correlation between Iranian EFL Learners' Use of Meta-cognitive Listening Strategies and Their Emotional Intelligence. International Education Studies, 5(6), 189-203. http://dx.doi.org/10.5539/ies.v5n6p189

Bar-On, R. (1988). The development of an operational concept of psychological wellbeing. Unpublished doctoral dissertation. Rhodes University, South Africa.

Bruer, J. T. (1995). Schools for Thought Cambridge. The MIT Press.

Boekaerts, M., \& Simons, P. R. J. (1993). Learn Instructive, Psychologies van de Leering Het Leer process (Learning and Instruction: Psychology of the learner and the Learning Process). Dekker \& Van de Vegt. Assen.

Jong, F. P. C. M. de. (1992). Zelfstandig leren. Regulative van het leerproces en leren reguleren: een procesbenadering. Academisch proefschrift, Tilburg: Katholieke Universiteit Brabant.

Flavell, J. (1985). Cognitive Development (2nd ed.). Englewood Cliffs, N.J: Prentice-Hall.

Flavell, J. (1979). Meta-cognition and meta-cognitive monitoring: A new area of cognitive developmental inquiry. American Psychologist, 34(10), 906-911. http://dx.doi.org/10.1037/0003-066X.34.10.906

Flavell, J. H. (1976). Meta-cognitive Aspects of Problem Solving. In L. B. Resnick (Ed), The Nature of Intelligence. Hillsdale, NJ: Erlbaum.

Flavell, J. H., \& Wellman, H. M. (1977). Meta-memory. In R. V. Kail, \& J. W. Hagen (Eds.), Perspectives on the development of memory and cognition (pp. 3-33). Hillsdale: Erlbaum.

Garnder, H. (1999). Intelligence reframed. New York: Basic Books.

Goleman, D. (1995). Emotional Intelligence: Why it can matter more than IQ. New York: Bantam Books.

Henson, K. T., \& Eller, B. F. (1999). Educational psychology for Effective Teaching (2nd ed.). Boston, Wadsworth Publishing Company.

Johnson, G. (2008). Learning Styles and Emotional Intelligence of the Adult Leaner. Unpublished Doctoral Dissertation, Auburn University, U.S.A.

Kluwe, R. (1982). Cognitive knowledge and executive control meta-cognition. In D. R. Girffin (Ed.), Animal Mind Human Mind (pp. 201-224). New York: Springer verlage.

Lindstrom, C. (1995). Empower The Child with learning Difficulties to Think Meta-cognitively. Australian Journal of Remedial, Education, 27(2), 28-31.

Livingston, J. A. (1997). Meta-cognition: An overview. Retrieved December 27, 2011, from http://gse.buffalo.edu/fas/shuell/CEP564/Metacog.htm

Mayer, J. D., \& Salovey, P. (1997). What is emotional intelligence? In P. Salovey, \& D. J. Sluyter (Eds.), Emotional development and emotional intelligence (pp. 3-31). New York, NY: Basic Books.

Matthews, G., \& Wells, A. (2004). Rumination, depression and meta-cognition: The S-REF model. In C. Papageorgiou, \& A. Wells (Eds.), Depressive rumination: Nature, theory and treatment. Chichester, UK: Wiley.

Paris, S., Lipson, M., \& Wixson, K. (1983). Becoming-strategic reader. Contemporary Educational Psychology, 8(3), 293-316. http://dx.doi.org/10.1016/0361-476X(83)90018-8

Paris, S. G., \& Jacobs, J. E. (1984). The benefits of informed instruction for children's reading awareness and comprehension skills. Child Development, 55, 2083-209. http://dx.doi.org/10.2307/1129781

Pfeiffer, S. I. (2001). Emotional intelligence: A popular but elusive construct. Report Review, 23, 138-142.

Resnick, L. B. (1989). Introduction. In L. B. Rudnick (Ed.), Knowing, learning and instruction (pp. 1-25). Hillsdale, NJ: Lawrence Erlbaum.

Salovey, P., \& Mayer, J. D. (1990). Emotional Intelligence. Imagination, Cognition and Personality, 9, 185-211.

Schraw, G., \& Dennison, R. (1994). Assessing meta-cognitive awareness. Cotemporary Educational Psychology, 
19, 460-475. http://dx.doi.org/10.1006/ceps.1994.1033

Simons, P. R. J. (2000). Review studied learner instructive. Nijmegen, The Netherlands: University of Nijmegen.

Sharei, M., Kazemi, F., \& Jafari, M. (2012). Investigation the effect of emotional intelligence skills and meta-cognitive capabilities on student's mathematical problem solving. Educational Research, 3(11), 844-850.

Wells, A. (2000). Emotional Disorders and Meta-cognition. New York: Wiley.

\section{Copyrights}

Copyright for this article is retained by the authors, with first publication rights granted to the journal.

This is an open-access article distributed under the terms and conditions of the Creative Commons Attribution license (http://creativecommons.org/licenses/by/3.0/). 